Pesq. Vet. Bras. 30(9):798-802, setembro 2010

\title{
Intraocular pressure and tear secretion in Saanen goats with different ages ${ }^{1}$
}

\author{
Alexandre Pinto Ribeiro², Dunia Yisela Trujillo Piso², Ivan Ricardo Martinez \\ Padua $^{2}$, Miguel Ladino Silva² and José Luiz Laus²*
}

\begin{abstract}
Ribeiro A.P., Piso D.Y.T., Padua I.R.M., Silva M.L. \& Laus J.L. 2010. Intraocular pressure and tear secretion in Saanen goats with different ages. Pesquisa Veterinária Brasileira 30(9):798-802. Departamento de Clínica e Cirurgia Veterinária, Universidade Estadual Paulista, Via de acesso Professor Paulo Donato Castellane s/n, Jaboticabal, SP 14870-000, Brazil. E-mail: jllaus@fcav.unesp.br

This study aimed to compare the normal intraocular pressure (IOP) and tear secretion, by means of applanation tonometry and the Schirmer tear test-1 (STT-1), in goats of the Saanen breed with different ages, and at different time points. Thirty six goats, free of ocular abnormalities, were grouped into three different age categories $(n=12)$, animals with 45,180 and 549 days of age. STT- 1 and IOP measurements were carried out always at 9:00am and 7:00pm, during three consecutive days. Results were evaluated statistically $(P<0.05)$. Regarding the time of the day, overall IOP values were significantly lower at 7:00 pm $(P<0.001)$ in individuals with 45 days of age; whereas STT-1 values were significantly higher at 7:00pm $(P=0.004)$ in goats with 549 days of age. Considering the sum of three days, both parameters were significantly lower in individuals with 45 days of age $(P<0.001)$. Intraocular pressure and tear secretion values increase until 180 days of age in the Saanen breed of goats.

INDEX TERMS: Ophthalmic semiotechnique, intraocular pressure, Schirmer tear test-1, goats.
\end{abstract}

RESUMO.- [Pressão intraocular e produção lacrimal em cabras da raça Saanen com diferentes idades.] Objetivou-se comparar os valores normais de pressão intraocular (PIO) e de produção lacrimal, através de tonometria de aplanação e do teste da lágrima de Schirmer-1 (TLS-1) em cabras da raça Saanen, com diferentes idades e momentos. Trinta e seis cabras da raça Saanen, livres de afecções oculares, foram agrupadas em três categorias etárias $(n=12)$, compreendendo animais com 45, 180 e 549 dias de idade. O TLS-1 e a PIO foram aferidos sempre às 9:00 e às 19:00, durante três dias consecutivos. Os resultados foram avaliados estatisticamente $(p<0,05)$. Relativamente ao horário do dia, a PIO foi significativamente menor às 19:00 ( $p<0,001)$ nos animais com 45 dias de idade; os valores do TLS-1 foram significativamente maiores às

\footnotetext{
${ }^{1}$ Received on July 14, 2010.

Accepted for publication on August 23, 2010.

2 Departamento de Clínica e Cirurgia Veterinária, Faculdade de Ciências Agrárias e Veterinárias (FCAV), Universidade Estadual Paulista (Unesp), Campus de Jaboticabal, Via de acesso Professor Paulo Donato Castellane s/n, Jaboticabal, SP 14870-000, Brasil. *Autor para correspondência: jllaus@fcav.unesp.br
}

19:00 ( $p=0,004)$ nas cabras com 549 dias de idade. Considerando-se a somatória dos três dias, ambos os parâmetros foram significativamente menores nos indivíduos com 45 dias de idade $(p<0,001)$. A pressão intraocular e a produção lacrimal em cabras da raça Saanen se elevam de forma significativa até os 180 dias de idade.

TERMOS DE INDEXAÇÃO: Semiotécnica oftálmica, pressão intraocular, teste da lágrima de Schirmer-1, cabras.

\section{INTRODUCTION}

It is important to study ophthalmopathies in food-producing animals as they play a significant role for economic losses; in addition to improvements made in ophthalmic research, where eyes of goats are commonly used with investigative purposes (Kohli \& Rai 1997, Sudan et al. 2002, Gilliland et al. 2005, Pawar \& Majumdar 2007).

Regarding the ophthalmic diseases of food-producing animals, infectious keratoconjunctivitis as one of the most important ilnesses in small ruminants (Whittaker et al. 1999, Gregory et al. 2003). Under such conditions, extra and intraocular changes may be perceived during routine ophthalmic examination (Whittaker et al. 1999). 
The Schirmer tear test-1 (STT-1) was first described by Otto Schirmer in 1903 and consists in using a Whatman number 41 special strip, $5 \mathrm{~mm}$ wide and $35 \mathrm{~mm}$ long, placed in the lower conjunctival fornix for one minute, with results reported in millimeters per minute (Hartley et al. 2005, Ribeiro et al. 2008a, Serruya et al. 2009). STT-2 evaluates basal tear production after topical application of an anesthetic and is of predictive value in animals with corneal ulceration that do not tolerate STT-1 (Ribeiro et al. 2008a). In accordance to Williams (2005), the wetting of the strip in one minute is related only to residual pre-existing tears in the conjunctival fornix, and four additional minutes are necessary to accurately evaluate tear reflex production. However, the one minute SST-1 remains the standard test to assess tear production in veterinary ophthalmology (Silva \& Galera 2004, Hartley et al. 2005, Piccioto et al. 2008, Ribeiro et al. 2008a, Piccioto et al. 2009).

Intraocular pressure (IOP) is maintained within a physiological range through a balance between aqueous humor production and outflow (Martins et al. 2009). In veterinary medicine, intraocular pressure is assessed accurately by means of applanation tonometry (Gelatt \& MacKay 1998, Kroll et al. 2001, Broadwater et al. 2007, Martins et al. 2007, Ribeiro et al. 2008b).

Standardization of ophthalmic parameters in goats is still sparse and needs to be improved (Galán et al. 2006, Broadwater et al. 2007, Whelan \& Thompson 2008, Ribeiro et al. 2009). To date, only two studies performed in this species evaluated tear secretion and intraocular pressure; however, such parameters were measured in a singular fashion, animals had the same age, and the effect of the time of the day was not assessed (Broadwater et al. 2007, Whelan \& Thompson 2008). Studies in attempt to standardize intraocular pressure and tear secretion at different hours of the day and in different situations have been carried out in dogs, cats and horses (Gelatt \& MacKay 1998, Hartley et al. 2005, Del Sole et al. 2007, Piccione et al. 2008a, 2009, Ribeiro et al. 2008b, Bertolucci et al. 2009). Goats present a higher level of activity in the middle of the day (Piccione et al. 2008b); for this reason, it is reasonable to hipothesize that intraocular pressure and tear secretion values as being lower during the evening.

The present article aims to compare normal values of intraocular pressure and tear secretion in Saanen goats with different ages and to evaluate if such parameters fluctuate between the morning and the evening.

\section{MATERIALS AND METHODS}

This study was approved by the Ethics Committee on Animal Experimentation of the Faculty of Agricultural and Veterinary Sciences (FCAV) of Sao Paulo State University (Unesp), Jaboticabal, São Paulo, Brazil, and followed the ethical guidelines of the Association for Research in Vision and Ophthalmology (ARVO, National Institutes of Health Publications no.85-23, revised 1985).

Thirty six Saanen goats were grouped into three different age categories $(n=12)$, which compromised animals with 45 (average weight of $4.33 \pm 1.46 \mathrm{~kg}$ ), 180 (average weight of
$30.62 \pm 4.51 \mathrm{~kg}$ ), and 549 days of age (average weight of $32.72 \pm 5.29 \mathrm{~kg}$ ) from the goat breeding section of the FCAV/ Unesp. Prior to selection, subjects underwent a full ophthalmic examination including dazzle and pupillary reflexes, slit lamp biomicroscopy ${ }^{3}$, binocular indirect ophthalmoscopy ${ }^{4}$, and fluorescein staining ${ }^{1}$. Only animals with no ocular abnormalities were enrolled in the study. After selection, goats were housed collectively, fed with silage $(70 \%)$ and balanced ration for the species $(30 \%)$, and water ad libitum. Two days prior to the beginning of the study, animals underwent physical restraint to acquaint them with procedures (intraocular pressure and Schirmer tear test-1), as well as with the investigators.

Schirmer tear test $-1^{6}$ was performed with strips inserted into the ventral conjunctival fornix for one minute, maintaining the palpebral fissure closed. After instillation of anesthetic eye drop ${ }^{7}$ at the ocular surface, intraocular pressure was measured by means of applanation tonometry ${ }^{8}$, considering values achieving less than $5 \%$ standard deviation at the instrument display. All measurements were recorded at 9:00am (light) and 7:00pm (dark), for three consecutive days, one hour after the animals were fed, during the month of May, by the same researcher.

Results are presented as mean and standard error of mean $( \pm$ SEM). Data were normally distributed ( $P>0.01$, KolmogorovSmirnov test). Results between right and left eyes, over time and between age groups were compared by one way repeated measures analysis of variance with Tukey as a post-hock test ${ }^{9}$. Overall differences between right and left eyes and between diurnal and nocturnal values were assessed by paired $\mathrm{T}$ test ${ }^{7}$. A value of $P<0.05$ was considered significant for all analysis.

\section{RESULTS}

\section{Intraocular pressure}

Overall intraocular pressure values between right $(\mathrm{RE})$ and left (LE) changed significantly in subjects with 45 $(7.77 \pm 0.29 \mathrm{mmHg} \mathrm{RE} ; 8.28 \pm 0.30 \mathrm{mmHg}$ LE; $P=0.02)$ and with 549 days of age $(9.36 \pm 0.27 \mathrm{mmHg} R E ; 10.24 \pm 0.33 \mathrm{mmHg} L E$; $P=0.004)$. In animals with 180 days of age, intraocular pressure did not change significantly between RE and LE ( $P=0.43$ ).

Between 9:00am and 7:00pm, significant changes $(P<0.0001)$ in overall intraocular pressure (IOP) values were observed only in goats with 45 days of age $(8.77 \pm 0.30 \mathrm{mmHg}$ 9:00am; $7.28 \pm 0.27 \mathrm{mmHg} 7: 00 \mathrm{pm})$. In goats with 180 days of age, IOP did not changed significantly $(P=0.78)$ between diurnal and nocturnal evaluations $(10.11 \pm 0.31 \mathrm{mmHg} 9: 00 \mathrm{am}$; $10.25 \pm 0.39 \mathrm{mmHg} 7: 00 \mathrm{pm})$. In animals with 549 days of age, overall IOP decreased $6.23 \%$ at $7: 00 \mathrm{pm}(10.11 \pm 0.31 \mathrm{mmHg}$ 9:00am.; $9.48 \pm 0.30 \mathrm{mmHg} 7: 00 \mathrm{pm})$, however, such variation was not significant $(P=0.11)$.

Throughout the study, mean intraocular pressure values assumed similar results in all age groups, until 9:00am of the second day of evaluation. From this time point, IOP decreased significantly $(P<0.001)$ in subjects with 45 days of age (Fig.1). The overall IOP values measured in each age group are summarized in Table 1.

\footnotetext{
${ }^{6}$ Teste de Schirmerâ, Ophthalomos, São Paulo, SP.

${ }^{7}$ Anestalcon, Alcon do Brasilâ, São Paulo, SP.

${ }^{8}$ Tonopen XL, Mentor O\&O, Norwell.

${ }^{9}$ Prism $4.0^{\circledR}$, GraphPad Software Inc., San Diego, CA, USA.
} 


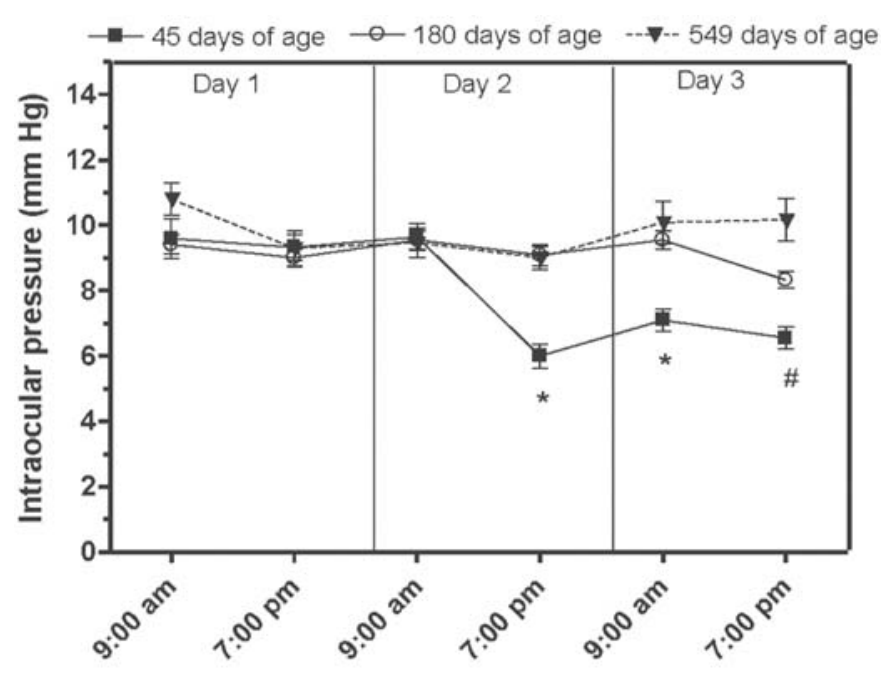

Time (hour)

Fig.1. Mean and standard error of mean of intraocular pressure $(\mathrm{mmHg})$ changes throughout the period evaluated, in Saanen goats aging 45, 180 and 549 days. *Tukey test $(P<0,001)$, in comparison to other ages. \#Tukey test $(\mathrm{P}<0,001)$, only related to individuals with 549 days of age.

Table 1. Descriptive statistic of intraocular pressure (mmHg) and Schirmer tear test-1 (millimeters/minute) values, after three consecutive days of evaluation, in Saanen goats aging 45, 180 and 549 days

\begin{tabular}{lccc}
\hline & 45 days & 180 days & 549 days \\
\hline Intraocular pressure & & & \\
Mean and SEM & & & \\
Maximum & 13.00 & 13.00 & 21.00 \\
Minimum & 4.00 & 6.00 & 4.00 \\
Confidence interval & 0.43 & 0.23 & 0.43 \\
Schirmer tear test-1 & & & \\
Mean and SEM & $10.38 \pm 0.23^{\star}$ & $14.83 \pm 0.33$ & $13.80 \pm 0.66$ \\
Maximum & 19.00 & 26.00 & 35.00 \\
Minimum & 3.00 & 8.00 & 4.00 \\
Confidence interval & 0.58 & 0.50 & 0.80 \\
\hline
\end{tabular}

\#Standard error of mean. *Tukey test $(P<0.001)$, in comparison to other ages.

\section{Schirmer tear test-1}

Overall Schirmer tear test-1 (SST-1) values between right (RE) and left (LE) did not change significantly in subjects with $45(10.20 \pm 0.39 \mathrm{~mm} / \mathrm{min}$. RE; $10.58 \pm 0.44 \mathrm{~mm} / \mathrm{min}$. LE; $P=0.44)$ and with 180 days of age $(14.59 \pm 0.42 \mathrm{~mm} / \mathrm{min}$. RE; $15.09 \pm 0.28 \mathrm{~mm} / \mathrm{min}$. LE; $P=0.24)$. Notwithstanding, in goats with 549 days of age, SST-1 results changed significantly between RE $(13.13 \pm 0.53 \mathrm{~mm} / \mathrm{min}$.) and LE $(14.49 \pm 0.60 \mathrm{~mm} /$ $\min$.) $(P=0.02)$.

Between 9:00am and 7:00pm, overall STT-1 values did not vary significantly in goats with $45(10.38 \pm 0.49 \mathrm{~mm} / \mathrm{min}$. 9:00am; $10.39 \pm 0.41 \mathrm{~mm} / \mathrm{min}$. 7:00pm; $P=0.97)$ and with 180 days of age $(15.23 \pm 0.28 \mathrm{~mm} / \mathrm{min}$. 9:00am; $14.45 \pm 0.32 \mathrm{~mm} /$ $\min$. $7 \mathrm{pm} ; P=0.11$ ). In goats with 549 days of age, however, overall STT-1 changed significantly $(P=0.004)$ between diurnal $(12.99 \pm 0.47 \mathrm{~mm} / \mathrm{min}$.) and nocturnal $(14.63 \pm 0.65 \mathrm{~mm} /$ min.) evaluations.
Throughout the study, mean Schirmer tear test-1 values assumed similar results in goats aging 180 and 549 days ( $P>0.05$ ). In individuals with 45 days of age, STT-1 values were significantly lower, in all but one time point evaluated $(P<0.001)$ (Fig.2). The overall STT-1 values measured in each age group are summarized in Table 1.

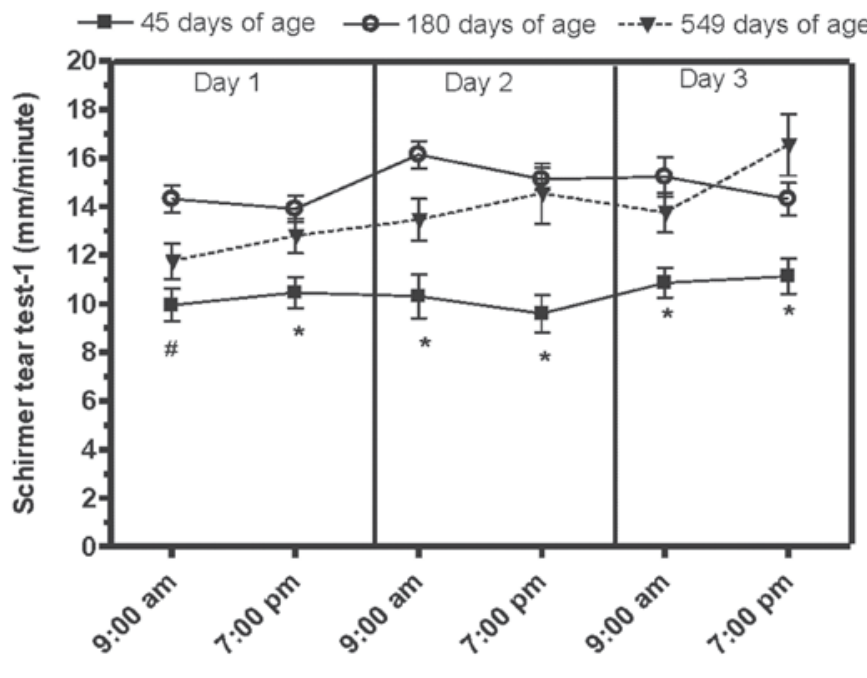

Time (hours)

Fig.2. Mean and standard error of mean of Schirmer tear test1 (millimeters per minute) changes throughout the period evaluated, in Saanen goats aging 45, 180 and 549 days.

*Tukey test $(P<0,001)$, in comparison to other ages.

\#Tukey test $(P<0,001)$, only related to individuals with 180 days of age.

\section{DISCUSSION}

The present article is the first one to show diurnal and nocturnal variation of intraocular pressure and tear secretion, in Saanen goats with different ages. Our results showed that overall intraocular pressure (IOP) values is significantly lower in goats with 45 days $(8.03 \mathrm{mmHg})$, when compared to IOP of individuals with $180(1.2 \mathrm{mmHg} / 12.24 \%$ higher) and with 549 days of age $(1.76 \mathrm{mmHg} / 17.97 \%$ higher). Our findings corroborate with those observed by Ofri et al. (2008), which described that IOP values in lions, increase until 20 months of age; in the same research, positive correlation between IOP, and size of the eye globe was also noted. Likewise, in marmosets, IOP values increase from the infancy, until the eye is fully developed (Nickla et al. 2002). Previous research showed that the cornea, anterior chamber, lens, vitreous chamber and axial globe length increased with age in the Saanen breed (Ribeiro et al. 2009). From these results, is reasonable to infer that in Saanen goats, axial globe length and IOP development occurs in parallel, until 180 days of age. It has been suggested that age-related changes in IOP of the developing eye serve as the driving force for the elongation and expansion of the eye (Ofri et al. 2008). In dogs, however, one study did not demonstrate a sustained elevation of IOP during maturation (Mughannam et al., 2004). In the 
Saanen breed, individuals are considered to be adults with 549 days of age (Ribeiro, 1998).

There is a trend of intraocular pressure being lower in geriatric cats (Kroll et al. 2001), dogs (Gelatt \& MacKay 1998), humas beings (Leske et al. 1997) and alligators (Whittaker et al. 1995). It is assumed the same to occur in Saanen goats. Notwithstanding, in pigmy goats with average age and weight of 7.9 years and $33.7 \mathrm{~kg}$, respectively, mean IOP values (10.8 $\pm 1.8 \mathrm{mmHg}$ ) (Broadwatter et al. 2007), were slightly higher than values seen in the present study in goats with 549 days of age $(9.79 \pm 0.27 \mathrm{mmHg})$. Likewise, in Angora goats, intraocular pressure of individuals with ages ranging from 5 months to 5 years was $4.11 \mathrm{mmHg}$ higher, than IOP of Saanen goats with 549 days of age (Whelan \& Thompson 2008).

The eye is considered to be the main source of photic information to the central pacemaker, being responsible to expresses circadian rhythms in various processes at all levels of organization from the molecular (e.g., melatonin synthesis), through the cellular (retinomotor movements, rod outer segment phagocytosis), whole organ (intraocular pressure), and visual system (visual sensitivity) levels (Nickla et al. 2002).

Regarding the impact of time of the day over IOP, fluctuations were observed in goats with 45 days of age. In this age group, overall IOP at 9:00 am was $1.49 \mathrm{mmHg}$ lower than values obtained at 7:00pm. In healthy horses, it is known that IOP values peak at the end of the light phase of the day, whereas lower values are seen in the morning time (Bertolucci et al. 2009). The same study showed that the rhythmicity of IOP persists when animals are kept under dark conditions; and it is abolished when they are housed in environments with constant illumination (Bertolucci et al. 2009). Healthy cats treated with ocular hypotensive agents, and in those with uveitis and glaucoma, IOP rhythmicity is maintained (with higher values at night), even when animals are kept under dark conditions (Del Sole et al. 2007, Ribeiro et al. 2008b). Although the caprine species are considered to have daily habits (Piccione et al. 2008b), studies evaluating periods longer than three days and performed under different conditions, seem to be necessary to clarify the importance of daily rhythmicity over IOP in this species.

One study showed that after instillation of different parasympatholytics in sheep, pupil diameter increased significantly, and IOP readings reduced but did not change significantly in comparison to baseline and fellow eye values (Crivelaro et al. 2010). Similar results were noted in horses receiving topical atropine (Mughannam et al. 1999). In the present study, pupil diameter enhancement might be occurred during nocturnal evaluations because of lower luminosity. Considering that the pupil anatomy shape of small ruminants and horses are very similar, such findings may explain the lower IOP readings observed during the night, in individuals with 45 and 180 days of age.

In regard to tear secretion, significant lower values were observed in subjects with 45 days of age $(10.38 \pm 0.23 \mathrm{~mm} /$ $\min$.), in comparison with goats with $180(4.45 \mathrm{~mm} / \mathrm{min}$./ $41.08 \%$ higher) and with 549 days of age $(3.42 \mathrm{~mm} / \mathrm{min} . /$ $33 \%$ higher). Similar results were showed in neonate dogs (Silva \& Galera 2004) and cats (unpublished results), indicating that in this period, the eye and adnexa are not completely developed. In human beings, however, only preterm infants secret lower amount of tears in comparison to term infants (Toker et al. 2002, Akar et al. 2004, Dogru et al. 2004). Schirmer tear test-1 values of goats with 45 , 180 and 549 days of age ranged from 8 to $35 \mathrm{~mm} / \mathrm{min}$. and were similar to those observed in pigmy goats $(10-30 \mathrm{~mm} /$ min.) (Broadwater et al. 2007).

Hartley et al. (2005) showed that in dogs, tear secretion increases the amount of 0.7 millimeters in the afternoon $(4: 00 \mathrm{pm})$, when compared to values taken in the morning (10:00am). Other study reported that in dogs, tear secretion increases 1.0 millimeter in the nocturnal period (9:00pm) (Piccione et al. 2009). Similar results were described in horses (Piccione et al., 2008a). In the present research, an enhancement of $1.64 \mathrm{~mm} / \mathrm{min}$. was noted during the nocturnal period $(7: 00 \mathrm{pm})$ in individuals with 549 days of age. Such event, however, did not repeat in goats with 45 and 180 days of age. In dogs and horses, it have been showed that tear secretion is linked to circadian rhythm; such rhythmicity is maintained, even when individuals underwent cycles of 12 hours of light and 12 hours of darkness, as well as cycles of 24 hour of constant darkness (Piccione et al. 2008a, 2009). Nonetheless, such rhythmicity is lost, when these species are housed in environments with constant light (Piccione et al. 2008a, 2009).

It has been showed in human beings, that significant lower Schirmer tear test-1 (STT-1) values are observed when the test is performed with closed eyelids (Serruya et al. 2009). In veterinary medicine, such comparison has never been carried out. Herein, we decided to perform all STT-1 with the eyelids held closed, because voluntary movements of the third eye lid of goats, normally ejected the strip out of the conjunctival fornix during the examinations.

The left eye showed statistically significant higher IOP and STT-1 values than the right eye of goats with 549 days of age. The same event was repeated in the left eyes of animals with 45 days of age, in regard to IOP values. Although differences of comparable magnitude between the two eyes have been previously reported in horses (Piccione et al. 2008a) and dogs (Piccione et al. 2009), no clear explanation is available for this binocular discrepancy. In addition, the two days of adaptation period may not been enough to goats with 45 days of age, justifying the high IOP values seen in the first three time points, followed by an abrupt decrease at the second day of the experiment.

Although all measurements taken in the present study have been occurred in females, Broadwatter et al. (2007) showed that gender did not play a significant role over IOP and SST-1 values in pigmy goats. The same have been reported in dogs, capybaras, and ferrets (Gelatt \& MacKay 1998, Mughannam et al. 2004, Montiani-Ferreira et al. 2006, 2008). 
Considering how the research has been conceived, it is concluded that intraocular pressure and tear secretion in Saanen breed of goats, increase in a significant manner until 180 days of age. More studies must to be performed in order to clarify the impact of circadian variations over intraocular pressure and tear secretion values in goats of this breed.

\section{REFERENCES}

Akar Y., Cira A., Apaydin C., Erman M.A. \& Yilmaz A. 2004. The effect of prematurity on tear production. Curr. Eye Res. 28(2):145-151.

Bertolucci C., Giudice E., Fazio F. \& Piccione G. 2009. Circadian intraocular pressure rhythms in athletic horses under different lighting regime. Chronobiol. Int. 26(2):348-358.

Broadwater J.J., Schorling J.J., Herring I.P. \& Pickett J.P. 2007. Ophthalmic examination findings in adult pygmy goats (Capra hircus). Vet. Ophthalmol. 10(5):269-273.

Crivelaro R.M., Ribeiro A.P., Teixeira P.P.M., Trujillo D.Y., Guimarães P.J. \& Laus J.L. 2010. Effects of different mydriatics on intraocular pressure, pupil size, rumen and intestinal motility in the normal sheep. Proc. Annual Scientific Meeting of the European College of Veterinary Ophthalmologists, Berlin, Germany, p.7.

Del Sole M.J., Sande P.H., Bernades J.M., Aba M.A. \& Rosenstein R.E. 2007. Circadian rhythm of intraocular pressure in cats. Vet. Ophthalmol. 10(3):155-161.

Dogru M., Karakaya H., Baykara M., Ozmen A., Koksal N., Goto E., Matsumoto Y., Kojima T., Shimazaki J. \& Tsubota K. 2004. Tear function and ocular surface findings in premature and term babies. Ophthalmol. 111(5):901-905.

Gelatt K.N. \& MacKay E.O. 1998. Distribution of intraocular pressure in dogs. Vet. Ophthalmol. 1(2/3):109-114.

Gilliland G.D., Gilliland G., Fincher T., Harrington J. \& Gilliland J.M. 2005. Assessment of biomechanics of orbital fracture: a study in goats and implications for oculoplastic surgery in humans. Am. J. Ophthalmol. 140(5):868-876.

Hartley C., Williams D.L. \& Adams J. 2006. Effect of age, gender, weight, and time of day on tear production in normal dogs. Vet. Ophthalmol. 9(1):53-57.

Kohli K.S., Rai D.V., Kumar P., Jindal V.K. \& Goyal N. 1997. Impedance of a goat eye lens. Med. Biol. Eng. Comput. 35(4):348-353.

Kroll M.M., Miller P.E. \& Rodan I. 2001. Intraocular pressure measurements obtained as part of a comprehensive geriatric health examination from cats seven years of age or older. J. Am. Vet. Med. Assoc. 219(10):1406-1410.

Leske M.C., Connell A.M., Wu S.Y., Hyman L. \& Schachat A.P. 1997. Distribution of intraocular pressure. The Barbados Eye Study. Arch. Ophthalmol. 115(8):1051-1057.

Martins B.C., Oriá A.P., Souza A.L., Campos C.F., Almeida D.E., Duarte R.A., Soares C.P., Zuanon J.A., Neto C.B., Duarte J.M., SchockenIturrino R.P. \& Laus J.L. 2007. Ophthalmic patterns of captive brown brocket deer (Mazama gouazoubira). J. Zoo. Wildl. Med. 38(4):526532.

Martins B.C., Ribeiro A.P., Laus J.L. 2009. Glaucoma, p.151-167. In: Laus J.L. (Ed.), Oftalmologia Clínica e Cirúrgica em Cães e em Gatos. Roca, São Paulo,

Montiani-Ferreira F., Mattos B.C. \& Russ H.H. 2006. Reference values for selected ophthalmic diagnostic tests of the ferret (Mustela putorius furo). Vet. Ophthalmol. 9(4):209-213.

Montiani-Ferreira F., Truppel J., Tramontin M.H., Vilani R.G. \& Lange R.R. 2008. The capybara eye: Clinical tests, anatomic and biometric features. Vet. Ophthalmol. 11(6):386-394.
Mughannam A.J., Cook C.S. \& Fritz C.L. 2004. Change in intraocular pressure during maturation in Labrador Retriever dogs. Vet. Ophthalmol. 7(2):87-89.

Nickla D.L., Wildsoet C.F. \& Troilo D. 2002. Diurnal rhythms in intraocular pressure, axial length, and choroidal thickness in a primate model of eye growth, the common marmoset. Invest. Ophthalmol. Vis. Sci. 43(8):2519-2528.

Ofri R., Steinmetz A., Thielebein J., Horowitz I.H., Oechtering G. \& Kass P.H. 2008. Factors affecting intraocular pressure in lions. Vet. J. 177(1): 124-129.

Pawar P.K. \& Majumdar D.K. 2007. In vitro permeation characteristics of moxifloxacin from oil drops through excised goat, sheep, buffalo and rabbit corneas. Pharmazie. 62(11):853-857.

Piccione G., Giannetto C., Fazio F. \& Giudice E. 2008a. Daily rhythm of tear production in normal horse. Vet. Ophthalmol. 11(Suppl.1):57-60.

Piccione G., Giannetto C., Casella S. \& Caola G. 2008b. Circadian activity rhythm in sheep and goats housed in stable conditions. Folia Biol. 56(3/4):133-137.

Piccione G., Giannetto C., Fazio F., Assenza A. \& Caola G. 2009. Daily rhythm of tear production in normal dog maintained under different Light/Dark cycles. Res. Vet. Sci. 86(3):521-524.

Ribeiro S.D.A. 1998. Caprinocultura: criação racional de caprinos. In: Ibid. (Ed.), Criação Racional de Caprinos. Nobel, São Paulo. 318p.

Ribeiro A.P., Brito F.L.C., Martins B.C., Mamede F. \& Laus J.L. 2008. Qualitative and quantitatives tear film abnormalities in dogs. Ciencia Rural 38(2): 568-575a.

Ribeiro A.P., Junior D.P., Champion T., Brunetto M.A., Camacho A.A. \& Laus J.L. 2008. Effects of topical levobunolol or fixed combination of dorzolamide-timolol or association of dorzolamide-levobunolol on intraocular pressure, pupil size, and heart rate in healthy cats. Arq. Bras. Med. Vet. Zootec. 60(5):1045-1052b.

Ribeiro A.P., Miguel L.S., Juliana P.R., Teixeira I.A.M.A., Souza A.L.G. \& Laus J.L. 2009. Ultrasonographic and echobiometric findings in the eyes of Saanen goats of different ages. Vet. Ophthalmol. 12(5):313317.

Serruya L.G., Nogueira D.C. \& Hida R.Y. 2009. Schirmer test performed with open and closed eyes: variations in normal individuals. Arq. Bras. Oftalmol. 72(1):65-7.

Silva E.G. \& Galera P.D. 2004. Evaluation of tear formation during neonatal period in small breed dogs, using the Schirmer tear test-1: STT-11 and STT-12 [Abstract]. Annual Meeting of the American College of Veterinarian Ophthalmologists, 2004, Washington, DC, USA. Vet. Ophthalmol. 7(6):437-453.

Sudan R., Titiyal J.S., Rai H. \& Chandra P. 2002. Formalin-induced cataract in goat eyes as a surgical training model for phacoemulsification. J. Cataract. Refract. Surg. 28(11):1904-1906.

Toker E., Yenice Ö., Ögüte M.S., Akman I., \& Özek E. 2002. Tear production during the neonatal period. Am. J. Ophthalmol. 133(6): 746-749.

Whelan N.C. \& Thompson D. 2008. Normal ophthalmic diagnostic test values in Angora goats. [Abstract]. Annual Meeting of the American College of Veterinarian Ophthalmologists, Boston, DC, USA. Vet. Ophthalmol. 7(6):419.

Whittaker C.J.G., Gelatt K.N. \& Wilkie D.A. 1999. Food animal ophthalmology, p.1117-11763. In: Gelatt K.N. (Ed.), Veterinary Ophthalmology. $3^{\text {rd }}$ ed. Lippincott Williams and Wilkins, Philadelphia.

Whittaker C.J., Heaton-Jones T.G., Kubilis P.S., Smith P.J., Brooks D.E., Kosarek C., Mackay E.O. \& Gelatt K.N. 1995. Intraocular pressure variation associated with body length in young American alligators (Alligator mississippiensis). Am. J. Vet. Res. 56(10):1380-1383.

Williams D.L. 2005. Analysis of tear uptake by the Schirmer tear test1 strip in the canine eye. Vet. Ophthalmol. 8(5):325-330. 